\section{Fair shares for Japanese}

SIR-Japan's government institutions are now advertising their scheme for hundreds of foreign postdoctoral fellows (see S. S. Siddiqui, Nature 340, 337; 1989 and recent advertisements in Nature Classified). It is good to know that our research institutions, as well as universities, have finally decided to open their doors to researchers from outside Japan. I welcome our government's decision to make its laboratories international; its efforts (including high payment) will be appreciated by foreign researchers and probably by politicians, in spite of the difficulties experienced by foreigners living in Japan.

At the same time, however, it is regrettable that non-tenure-track Japanese researchers cannot similarly join laboratories as fellows. The time is now ripe for our laboratories and universities (both now training too few post-PhD fellows) to show Japanese PhDs how they can carry out postdoctoral research in their own country. If it does not do so, Japan will miss an opportunity to keep promising young scientists wanting experience in laboratories in different fields.

YASUSHI SAOTOME

M.D. Research Co. Ltd,

760 Morooka, Kohuku,

Yokohama 222.

Japan

SIR-I read with interest the article by S. Berliner III (Nature 341, 379; 1989) pointing out the difficulties of using the 2,000 characters of the Japanese language. As he recommended, the Japanese should, as a short-term measure, use bilingual signs in Japanese and English in public places, and should transcribe Japanese characters into roman letters for foreigners. As a long-term solution, however, do we really have to reform our language, which has the merits of both ideograms and phonetic signs? During my five years in New York, $I$ found that English-speaking people overlook the fact that the language-brain interface is more important than the language-machine interface.

If a sentence written with simple characters like the alphabet is easy to understand, why is machine language composed of only 0 and 1 so difficult for humans? The brain is well suited to recognizing patterns such as faces (Brain Res. 342, 91; 1985) and ideograms, and a concept is easily associated with the corresponding ideograms even in a patient with aphasia (Cortex 8, 265; 1972). Japanese sentences are easy to read because they are composed of lexical portions, written with katakanas (phonetic signs to express foreign words) and 1,945 basic Chinese characters, and grammatical formatives with hiraganas (the other phonetic signs).

In fact, the circulation of newspapers in
Japan is the highest (58 per cent) in the world (20 per cent in the United States), and many attempts to persuade Japanese to read newspapers and textbooks written in English or roman-lettered Japanese have failed. The percentage of total time spent on language during elementary school is only 25 per cent in Japan but over 40 per cent in the United States, and there is almost no illiteracy in Japan. This easy Japanese education has resulted in a flourishing society.

The disadvantage of Japanese in writing has now been overcome by the widespread use of Japanese word processors and facsimile machines. Memorizing ideograms is easy for children, but not for adults. Thus, millions of biological species and chemical compounds must be written in katakana instead of 80,000 complicated Chinese characters (Biochem. Educ. 16, 37; 1988).

People should choose a language suitable for both their brain and their culture, not for the typewriter.

YASUO KagaWA

Department of Biochemistry,

Jichi Medical School,

Tochigi, 329-04, Japan

\section{Don't blame us}

SIR-Your leading article "Research by numbers" (Nature 341, 674; 1989) quotes from a document setting out new resource management arrangements agreed last April between the Department of Education and Science (DES), the Treasury and the research councils, and wrongly suggests that these arrangements provided the basis for the government's decision not to finance the proposed national survey of sexual attitudes and behaviour.

Your readers will want to know that under these arrangements it is for the research councils to decide whether to refer matters to the DES. The initiative in seeking ministerial guidance is placed with the research councils, not with ministers.

In the case of this survey, the government decided it would not be appropriate to provide financial support from the Department of Health's research programme or, more generally, to sponsor the survey. The Economic and Social Research Council (ESRC) decided not to proceed on this basis. Contrary to your account, the ESRC was not required to refer the matter to the DES: nor did it do so.

The resource management agreement was concluded after extensive discussion between the department and all the research councils. It is designed to give greater freedom to councils in exchange for departmental scrutiny of councils' management systems. It is not the purpose of the new arrangements to limit councils' freedom nor to intervene directly in their scientific judgements. Any such agreement would have been unacceptable to the councils which continue to operate under the well established 'armslength' relationship with the government, embodied in the 1965 act establishing the research councils.

ROBERT JACKSON

(Parliamentary UnderSecretary of State)

Department of Education and Science, Elizabeth House,

York Road, London SE1 7PH, UK

\section{Creative force?}

SIR-If A. Travis (Nature 341, 10; 1989) is personally having "flirtations with the untestable" and holds the belief that there is a "creative force manifesting itself in the observable universe", how does telling us this assist in furthering our understanding of nature? Surely you have received correspondence from others on more important and specific topics that better deserve column space?

The essential difference between religious beliefs such as Travis's and the "organized common sense" of science is that religion demands explanations, while science is, or should be, prepared to answer: Nobody knows", and continue with its investigations.

Formulating unanswerable questions and then demanding answers to them is a waste of time. Formulating a theory to explain a feature of nature and then finding ways to test the theory is not. If a way is not found to test the theory, then it must be shelved until one is. A theory that life evolved here on Earth out of molecular interactions is in principle testable: for example, we can perform individual steps in the process experimentally, we can simulate it in our computers and we may one day be able actually to do the whole thing ourselves. The theory may be proved wrong, so therefore it is testable. No one has come up with a testable alternative yet, so if this one is proved wrong, we must return to "Nobody knows".

Travis looks for and finds some "unknown creative force" in this theory. That can only stem from his own religious desires for there to be one, for there is no mention of one in any of the statements of the theory that I have read.

To me, the conclusion "Nobody knows" is far more awe-inspiring and stimulating than "we can't explain this, so therefore there is a mysterious creative force in the universe", which in my opinion simply shows a lack of imagination.

K. P. APPLEBY

35 Catherine Street

Cambridge CB1 $3 A W$, UK 